\title{
Livros do FNDE (MEC): análise dos acervos e possibilidades de uso para atividades de leituras significativas
}

\author{
Juliana Aparecida Melo Almeida da Silva \\ Universidade de Taubaté
}

\begin{abstract}
Resumo
Este artigo apresenta dados de uma pesquisa sobre possibilidades de uso dos acervos oferecidos às escolas pelo FNDE/PNBE (MEC). O objetivo deste estudo foi fazer um levantamento e uma análise dos acervos de livros oferecidos pelo FNDE/PNBE (MEC) a fim de agrupá-los por gêneros discursivos e propor atividades de leitura significativas para os alunos do Ensino Fundamental II. O resultado do levantamento e análise dos 89 livros, mostrou a possibilidade de agrupa-los, em estações de acordo com os gêneros discursivos. Para cada estação foi sugerida uma ficha de leitura para orientar os procedimentos de levantamento de conhecimentos prévios sobre o gênero, de leitura global, estabelecimento de objetivos de leitura para o livro escolhido e de apreciação crítica do livro. Conclui-se que assim, é possível contribuir com uma prática pedagógica coerente, apoiada em fundamentação teórica indicada para o trabalho com leitura de diversos gêneros discursivos, despertando o gosto pela leitura.
\end{abstract}

Palavras-chave: Leitura; Textos literários; Acervo FNDE; Atividades significativas.

\begin{abstract}
This article presents data from a survey about the possibilities for the use of collections offered to schools by the ENDF / PNBE (MEC). The objective of this study was to survey and analyze the collections of books offered by the ENDF / PNBE (MEC) in order to group them by discursive genres and propose significant reading activities, especially for elementary school II students. The result of the survey and analysis of the 89 books in the collections showed how they can be grouped in stations according to genres. For each station, a reading sheet was suggested to guide the procedures for gathering prior knowledge of genres, for global reading, and for setting reading goals for the chosen book and critical appreciation of the book. Finally, this kind of study can contribute to a coherent pedagogical practice based on a theoretical framework suitable for the work with reading different genres, and it can consequently stimulate the taste for reading.

Keywords: Reading; Literay texts; FNDE acquisition; Significant activities.
\end{abstract}

\section{INTRODUÇÃO}

Este artigo apresenta dados de uma pesquisa sobre o levantamento de possibilidade de uso do acervo oferecido pelo FNDE/PNBE - MEC - para o 
desenvolvimento de aulas significativas de leitura. O desenvolvimento de habilidades de leitura nas aulas de Língua Portuguesa ainda impõe um desafio aos professores. Os profissionais entendem que esse trabalho é necessário, mas isso não elimina a importância de despertar o gosto por esta atividade, principalmente nos alunos do Ensino Fundamental II. Muitas vezes os próprios professores, por terem que dar conta de inúmeras tarefas, em sala de aula como: planejamento, aulas para diversas turmas, perdem essa perspectiva ou não têm ideia do que fazer com materiais que chegam às escolas. Na rede municipal há uma quantidade de livros, de boa qualidade, mas faltam ideias ou propostas para o trabalho docente.

O objetivo deste estudo foi fazer um levantamento e análise dos acervos de livros do ano de 2013 oferecidos pelo FNDE/PNBE - MEC - a fim de agrupá-los por gêneros discursivos e propor atividades de leitura significativa para que os professores de Língua Portuguesa do Ensino Fundamental II atuem como mediadores, conheçam o teor dos livros e usem-nos explorando melhor suas potencialidades, fomentado a leitura na escola.

Dúvidas frequentes sobre atividades de leitura nas aulas de Língua Portuguesa são: (i) Como despertar o gosto pela leitura nos alunos do Ensino Fundamental II?; (ii) Quais livros utilizar para o desenvolvimento de atividades de leitura?; (iii) Quais atividades poderiam ser realizadas em sala para um trabalho significativo de leitura?; (iv) Como trabalhar com os livros oferecidos pelo FNDE/MEC em sala de aula?

Espera-se que esta pesquisa possa contribuir com professores de Língua Portuguesa para o desenvolvimento de aulas significativas de leitura aos alunos do Ensino Fundamental II, oferecendo-lhes os acervos distribuídos que contêm uma diversidade de gêneros, temas, estilos, criando condições para a formação de leitores de mundo.

Esta pesquisa parte do pressuposto de que a literatura é um direito dos alunos (CANDIDO, 1995); de que a escola tem que instigar o aprendiz a ler e a fruir a literatura, desenvolvendo um olhar mais sensível e amplo da realidade, como afirma Pinto (2014); de que a experiência e a reflexão da leitura literária "podem ser mediadas e socializadas no espaço da sala de aula' (DALVI; REZENDE; JOVIER-FALEIROS, 2013, p. 13); e que o professor pode contribuir com procedimentos que ampliem as habilidades de leitura dos alunos (CEREJA, 2005; LOPES-ROSSI, 2005), entre outros autores. 
A metodologia da pesquisa consiste em analisar os livros dos acervos: caixa 1, caixa 2 e caixa 3, oferecidos pelo governo federal em 2013 a uma determinada escola. Após a análise, realizar o agrupamento dos livros de acordo com os gêneros. Trata-se de uma pesquisa de caráter bibliográfico e análise quantitativa de livros. Em seguida, serão propostas atividades para o desenvolvimento de leitura com cada um dos agrupamentos que possam subsidiar o trabalho docente. As propostas de atividades de leitura fundamentam-se numa perspectiva de educação literária complexa, "no sentido de propiciar condições, oportunidades, espaços e metodologias, de forma rigorosa, que assegurem ao estudante explorar ao máximo as potencialidades do texto artístico e expandir seu ângulo de percepção", como explica Pinto (2014, p. 125).

Este artigo se organiza em seções que apresentam a fundamentação teórica sobre a concepção de leitura literária que dará suporte às propostas de atividades, a análise dos livros dos acervos, agrupamento dos livros de acordo com o gênero e se encerra com propostas de atividades de leitura para cada um dos agrupamentos.

\section{FUNDAMENTAÇÃO TÉORICA}

De acordo com Candido (1995), a literatura é direito de todos e assim como o cidadão tem direito à alimentação, saúde e lazer, também tem o direito à arte e à literatura. $\mathrm{O}$ autor afirma que reconhecer que aquilo que consideramos indispensável para nós, deveria ser também indispensável para o outro e que todas as pessoas têm o direito aos "bens incompressíveis", que são: a alimentação, saúde, educação e lazer, porém, não achamos necessário e não consideramos como direito de todos "os bens compressíveis", como por exemplo, o acesso à cultura.

O mesmo autor esclarece que a literatura deve ser considerada como um bem incompressível, já que corresponde a necessidades profundas do ser humano, podendo atuar como condição de humanização, e que aparece como manifestação universal de todos os homens em todos os tempos, constituindo um direito a qualquer cidadão.

Candido (1995) relaciona a literatura com os direitos humanos sob dois aspectos diferentes. Primeiro verifica que a literatura corresponde a uma necessidade universal, porque dá forma aos sentimentos e à visão de mundo e no segundo confere à literatura um poder consciente de desmascaramento, pois revela as situações de restrição dos direitos, ou de ligação a eles. 
Considerando o texto literário como objeto central de estudo, vale ressaltar que Cereja (2005) se remete a esse autor, quando diz que a literatura, possui um papel formador para a cidadania, a ponto de ser considerado humanizador. Para o pesquisador, além dessa função ideológica, possui a função primordial de ensinar a ler, desenvolvendo habilidades essenciais para a formação de um leitor autônomo e competente.

Cereja (2005) afirma que as habilidades de leitura desenvolvidas perpassam o nível de leitura global e permeiam habilidades muito mais complexas do que as de identificar, classificar e memorizar, e trabalham com a identificação de temas, informações implícitas e explícitas, levantamento de hipóteses, seleção de informações, inferência, justificativa, análise, comparação e interpretação, permitindo uma leitura muito mais significativa.

Ainda sobre isso, Maria (2008) diz que o texto só se completa com a leitura. A cada leitura que faz, o leitor atualiza seus conhecimentos. Isso torna o texto plurissignificativo. Dependendo das vivências que o leitor possui sobre determinado texto, o nível de leitura que o mesmo possui e as informações prévias sobre o assunto, a atribuição de sentidos será maior e consequentemente melhor interpretação e compreensão. A cada texto que lemos, a cada conhecimento que adquirimos, a cada nova experiência que vivemos, aprofundamos o nosso aprendizado e nos tornamos melhores leitores.

Nesse sentido, ao trazermos esses conceitos para a escola, Maria (2008) afirma que a função dos professores não é tanto ensinar as crianças a lerem, mas ajudá-las a lerem. É essencial que deixamos de considerar somente a leitura para busca de informações, mas que promovamos leituras com diferentes objetivos e que consideremos a experiência do leitor.

A pesquisadora salienta que a experiência na leitura produz sempre mais conhecimento sobre a própria leitura, de modo que aqueles que leem muito, sem dúvida tendem a ler melhor. Para a autora, a leitura é considerada pensamento à medida que há a interação do leitor com o texto. Por esse processo, a leitura possui implicação direta com o desenvolvimento cognitivo, com a interação e o diálogo. No processo da leitura, a criança tem a oportunidade de testar suas posições, inteirando-se com realidades diversas, confrontando-se com o outro, aceitando o diferente e ampliando o seu universo.

Maria (2008) ainda considera a leitura como a possibilidade de diálogo para além do tempo e do espaço. Ressalta que essa é o alargamento do mundo para além dos limites 
de quatro paredes, possibilita experiências das mais variadas e imaginárias, permite viajar para locais nunca conhecidos, com quem quer que queiramos, mesmo que estejamos sozinhos, abre caminhos para a criatividade e conhecimentos de culturas e momentos históricos nunca afamados.

Para complementar, vale ressaltar o papel da escola frente à formação do leitor, principalmente, o leitor literário. Segundo Coelho (2000), a escola é, hoje, o espaço privilegiado, em que deverão ser lançadas das bases para a formação do indivíduo e que a literatura tem a tarefa fundamental de servir como agente de formação na sociedade em transformação, seja no espontâneo convívio leitor/livro, seja no diálogo leitor/texto estimulado pela instituição escolar. Coelho (2000) afirma que a literatura é o agente ideal para a formação da nova mentalidade e que a maior responsabilidade na formação da consciência de mundo das crianças e jovens deve ser atribuída ao livro. Mediante a isso, a literatura precisa ser muito menos descoberta como mero entretenimento e muito mais uma aventura espiritual que engaje o eu em uma experiência rica de vida, inteligência e emoções.

\section{PROCEDIMENTOS METODOLÓGICOS}

Para realizar este trabalho, foi utilizado um corpus composto por três caixas com 89 livros no total. O corpus consiste em livros de literatura de gêneros variados pertencentes a três acervos, identificados pelo Programa Nacional Biblioteca da Escola (PNBE) como: Acervo PNBE2013- Caixa1, Acervo PNBE2013- Caixa 2, Acervo PNBE2013-Caixa 3, a seguir: 
Imagem 1: Acervo PNBE2013- Caixa 1

\section{1. \\ MINISTÉRIO DA EDUCAÇÃO \\ FUNDO NACIONAL DE DESENVOLVIMENTO DA EDUCAÇĀO}

Informe nº 32/2013 - COARE/CGPLI/DIRAE/FNDE/MEC

Brasília, setembro de 2013.

Senhor(a) Diretor(a)

. F Fundo Nacional de Desenvolvimento da Educação (FNDE) está enviando à sua escola, de setembro a novembro de 2013, acervos literários relativos ao Programa Nacional Biblioteca da Escola - PNBE 2013, para atendimento aos alunos do $6^{2}$ ao $9^{\circ}$ ano do ensino fundamental. As obras relacionadas abaixo são direcionadas biblioteca, devendo ser incorporadas ao acervo bibliográfico da escola. 2. Informações sobre a distribuição dos acervos estāo disponiveis na Internet, no portal do FNDE, em
wherw finde gov br $\gg$ Consultas Online $\gg$ Distrlbuição de llvros, selecionando o ano 2013 e o programa PNBE, e em seguida localizando a UF e o Município. Depois basta indicar a escola correspondente e clicar em Pesquisar.

3. Esclarecimentos complementares podem ser obtidos no portal do FNDE, $\in m$ Programas $\gg$ Livro Didático, ou ainda junto ao Serviço de Atendimento ao Cidadăo (SAC), pelo telefone 0800616161 (ligaçăo graiuita).

PNBE 2013 FF1 - CAIXA 1

\begin{tabular}{|c|c|c|c|c|c|}
\hline $\mathrm{N}^{\mathbf{2}}$ & TÍTULO & EDITORA & № & Título & EDTTORA \\
\hline 1 & A Fillha das Sombras & Edelbra Gráfica & 16 & O Desaparecimento de Katharina Linden & Eóitora Bertrand Brasil \\
\hline 2 & A Mocinha do Mercado Central & Editora Globo & .17 & O Diário de Dan & Editora Plancta do Brasil \\
\hline 3 & $\begin{array}{l}\text { Anlta Garibaldi - A Estreia da } \\
\text { Tempestade }\end{array}$ & Sociedada Literária & 18 & O Enigma de Iracema & $\begin{array}{l}\text { Escala Empresa de } \\
\text { Comunicaçāo Integrada }\end{array}$ \\
\hline 4 & Antologia de Contos Folclóricos & Edioura Publicaçōes & 19 & O Homăo e o Menininh & Abacattle Editorial \\
\hline 5 & Aqualtune $\theta$ as Hisiórias da África & Editora Gaivota & 20 & O Leāo da Noitte Estrelada & Saraiva $\Theta$ Sigiliano \\
\hline 6 & $\begin{array}{l}\text { As Aventuras de Max e Seu Oiho } \\
\text { Submarino }\end{array}$ & Editora UDP & 21 & O Lureiro do Alemăo & $\begin{array}{l}\text { Guia dos Curiosos } \\
\text { Comunicaçбes } \\
\end{array}$ \\
\hline 7 & As Aventuras de Tom Sawyer & $\begin{array}{l}\text { Editora } \\
\text { Melhoramentos } \\
\end{array}$ & 22 & O Livro Negro de Thomas Kyd & Editora FTD \\
\hline B & $\begin{array}{l}\text { As Melhores Historlas das Mil e Uma } \\
\text { Noites }\end{array}$ & Ediouro Gréfica & 23 & O Mundo de Cannila & Edilora Projeto \\
\hline 9 & $\begin{array}{l}\text { Charles Darwin: O Segredo da } \\
\text { Evoluçăa }\end{array}$ & Editora Miguilim & 24 & Os Passarinhos e Outros Bichos & Kroll Tudrey e Yacubian \\
\hline 10 & Diário do Outro & Saraiva & 25 & Os Pequenos Verdes $\theta$ Outras Historias & Berlendis Editores \\
\hline 11 & Duelo & Editora Claro Enigma & 26 & Robin Hood & Manole \\
\hline 12 & Era Uma Vez à Msia-Noite & Editora Best Seller & 27 & Sortes de Villamor & Edittra Scipione \\
\hline 13 & $\begin{array}{l}\text { Histórias Arreplantes de Crianças- } \\
\text { Prodígio }\end{array}$ & Editora Schwarcz & 28 & Tem Uni Morcego no Meu Pombal & Cata-Sonho Editora \\
\hline 14 & O Cara & Editora UDP & 29 & Viagem Numa Peneira & Editora lluminuras \\
\hline 15 & O Chamado do Monstro & Editora Atica & & & \\
\hline
\end{tabular}

FUNDO NACIONAL DE DESENVOLVIMENTO DA EDUCAÇÃO

Fonte: BRASIL (2013). 
Imagem 2: Acervo PNBE2013- Caixa 2

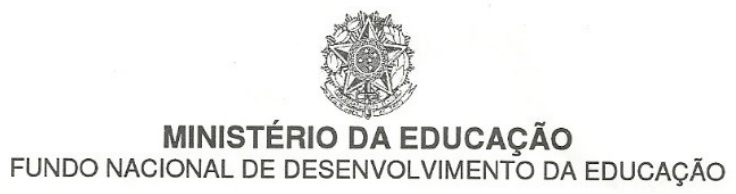

Informe n 35/2013 - COARE/CGPLI/DIRAE/FNDE/MEC

Brasília, setembro de 2013

Senhor(a) Diretor(a)

1. O Fundo Nacional de Desenvolvimento da Educação (FNDE) está enviando à sua escola, de setembro a novembro de 2013, acervos literários relativos ao Programa Nacional Biblioteca da Escola - PNBE 2013, para atendimento aos alunos do $6^{\circ}$ ao $9^{\circ}$ ano do ensino fundamental. As obras relacionadas abaixo são direcionadas à biblioteca, devendo ser incorporadas ao acervo bibliográfico da escola.

2. Informações sobre a distribuição dos acervos estão disponíveis na Internet, no portal do FNDE, em www.fnde.gov.br $\gg$ Consultas Online $\gg$ Distribuição de livros, selecionando o ano 2013 e o programa PNBE, e em seguida localizando a UF e o Município. Depois basta indicar a escola correspondente e clicar em Pesquisar.

3. Esclarecimentos complementares podem ser obtidos no portal do FNDE, em Programas >> Livro Didático, ou ainda junto ao Serviço de Atendimento ao Cidadão (SAC), pelo telefone 0800616161 (ligação gratuita).

PNBE 2013 FF2 - CAXA 2

\begin{tabular}{|c|c|c|c|c|c|}
\hline № & TítULO & EDITORA & № & TítULO & EDITORA \\
\hline 1 & As Mil e Uma Noites & Editora Revan & 16 & Meu Coração É Tua Casa & Comboio de Corda Editora \\
\hline 2 & 1001 Fantasmas & A Página Distribuidora de Livros & 17 & Moça Lua e Outras Lendas & Ediouro Publicações \\
\hline 3 & A Escrava Isaura & $\begin{array}{l}\text { Sistemas de Ensino Abril } \\
\text { Educacao }\end{array}$ & 18 & O Burrinho Pedrês & Ediouro Publicações \\
\hline 4 & A Primeira Vez Que Vi Meu Pai & Artes e Ofícios Editora & 19 & O Chute Que a Bola Levou & Editora Moderna \\
\hline 5 & A Reforma da Natureza & Editora Távola Infanto Juvenil & 20 & O Doente Imaginário & Editora 34 \\
\hline 6 & A Roda do Vento & Distrrecord de Serv. de Imprensa & 21 & O Flautista De Hamelin & Ediçöes SM \\
\hline 7 & A Tatuagem - Reconto do Povo Luo & Editora Gaivota & 22 & $\begin{array}{l}\text { O Gato Do Xeique E Outras } \\
\text { Lendas }\end{array}$ & Ediouro Publicações \\
\hline 8 & Com Certeza Tenho Amor & Gaudi Editorial & 23 & O Que a Terra Está Falando & Edelbra Gráfica \\
\hline 9 & Dom Quixote em Cordel & Manole & 24 & Os Noivos & Editora Record \\
\hline 10 & É Fogo! & In Pacto Comércio de Revistas & 25 & O Outro Passo da Dança & Artes e Ofícios Editora \\
\hline 11 & $\begin{array}{l}\text { Fotografando Verger (Coleção } \\
\text { Memória e História) }\end{array}$ & Editora Claro Enigma & 26 & Pescador de llusões & $\begin{array}{l}\text { Barba Negra Produção } \\
\text { Cultural }\end{array}$ \\
\hline 12 & $\begin{array}{l}\text { Histórias para Jovens de Todas as } \\
\text { Idades }\end{array}$ & $\begin{array}{l}\text { Editora Nova Fronteira } \\
\text { Participaçōes }\end{array}$ & 27 & $\begin{array}{l}\text { Sangue de Dragão - Palco De } \\
\text { Paixões }\end{array}$ & Editora FTD \\
\hline 13 & Lampião na Cabeça & Editora Rocco & 28 & $\begin{array}{l}\text { Sete Histórias de Pescaria do Seu } \\
\text { Vivinho }\end{array}$ & Abacatte Editorial \\
\hline 14 & Livro de Recados & In Pacto Comércio de Revistas & 29 & Três Anjos Mulatos do Brasil & Editora FTD \\
\hline 15 & $\begin{array}{l}\text { Mary Shelley: O Mistério da } \\
\text { Imortalidade }\end{array}$ & Base Editorial & 30 & Um Sonho no Caroço do Abacate & Global Editora \\
\hline
\end{tabular}

FUNDO NACIONAL DE DESENVOLVIMENTO DA EDUCAÇÃO

Fonte: BRASIL (2013). 
Imagem 3: Acervo PNBE2013- Caixa 3

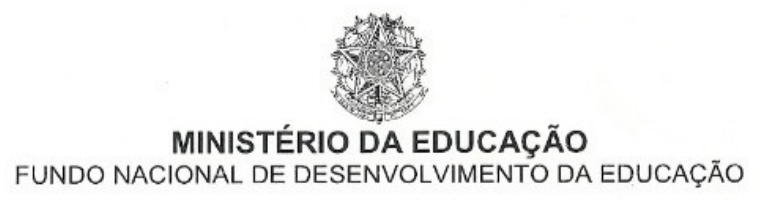

Informe $n^{\circ} 37 / 2013$ - COARE/CGPLI/DIRAE/FNDE/MEC

Brasilia, setembro de 2013.

Senhor(a) Diretor(a)

1. O Fundo Nacional de Desenvolvimento da Educação (FNDE) está enviando à sua escola, de setembro a novembro de 2013, acervos literários relativos ao Programa Nacional Biblioteca da Escola - PNBE 2013, para atendimento aos alunos do $6^{\circ}$ ao $9^{\circ}$ ano do ensino fundamental. As obras relacionadas abaixo săo direcionadas à biblioteca, devendo ser incorporadas ao acervo bibliográfico da escola.

2. Informações sobre a distribuição dos acervos estäo disponiveis na Internet, no portal do FNDE, em www.fnde.qov.br $\gg$ Consultas Online $\gg$ Distribuição de livros, selecionando o ano 2013 e o programa PNBE, e em seguida localizando a UF e o Municipio. Depois basta indicar a escola correspondente e clicar em Pesquisar.

3. Esclarecimentos complementares podem ser obtidos no portal do FNDE, em Programas $\gg$ Livro Didático, ou ainda junto ao Serviço de Atendimento ao Cidadão (SAC), pelo telefone 0800616161 (ligação gratuita).

PNBE 2013 FF3 - CAIXA 2

\begin{tabular}{|c|c|c|c|c|c|}
\hline $\mathrm{N}^{\circ}$ & TítULO & EDITORA & $\mathrm{N}^{\circ}$ & TítULO & EDITORA \\
\hline 1 & A Criaçăo das Criaturas & Ediçбes SM & 16 & Menino Perplexo & Editora Dublinense \\
\hline 2 & A Fábrica de Robôs & Hodra Educaçăo & 17 & Moby Dick & Editora Moitara \\
\hline 3 & A Jornada & NC Editora & 18 & $\begin{array}{l}\text { Ninguóm Me Entende Nessa } \\
\text { Casal Crônicas e Casos }\end{array}$ & Editora FTD \\
\hline 4 & A Vaca na Selva & Gaudi Editorial & 19 & O Fantasma de Canterville & Companhia Editora Nacional \\
\hline 5 & $\begin{array}{l}\text { A Volta às Aulas do Pequeno } \\
\text { Nicolau }\end{array}$ & Editora Rocco & 20 & O Livro dos Dragões & Editora Hedra \\
\hline 6 & As Memórias de Eugênia & Gráfica E Editora Posigraf & 21 & O Livro Selvagem & $\begin{array}{l}\text { A Página Distribuidora De } \\
\text { Livros }\end{array}$ \\
\hline 7 & Atrás do Paraiso & Joso Olympio Editora & 22 & O Mistério do Cinco Estrelas & Gaudi Editorial \\
\hline 8 & Desculpe a Nossa Falha & $\begin{array}{l}\text { Sistemas de Ensino Abril } \\
\text { Educacao }\end{array}$ & 23 & O Senhor dos Ladrōes & $\begin{array}{l}\text { A Página Distribuidora de } \\
\text { Livros }\end{array}$ \\
\hline 9 & Era Uma Vez. Esopo & DCLDifusao Cultural do Livro & 24 & $\begin{array}{l}\text { O Tempo Escapou do Relógio e } \\
\text { Outros Poemas }\end{array}$ & Editora Piá \\
\hline 10 & Fantástica Fábrica de Chocolate & Livraria Martins Fontes Editora & 25 & Orixás: Do Orum ao Ayê & NBL Editora \\
\hline 11 & Histórias de Bichos & Editora Atica & 26 & $\begin{array}{l}\text { Păo Feito Em Casa - Trê Jovens. } \\
\text { Uma Receita. Alguns Segredos. }\end{array}$ & Ediçōes Besourobox \\
\hline 12 & Histórias de Mistério & Editora Schwarcz & 27 & Poetrix & Signo Editora \\
\hline 13 & Isso Ninguém Me Tira & Editora Ática & 28 & Raul Taburin & Cosac \& Naify Ediçöes \\
\hline 14 & Justino, O Retirante & Saraiva e Siciliano & 29 & Se a Memória Não Me Falha & Vida Melhor Editora \\
\hline 15 & Menino do Mato & Texto Editores & 30 & Vocè è Livre! & Autènt ca Editora \\
\hline
\end{tabular}

FUNDO NACIONAL DE DESENVOLVIMENTO DA EDUCAÇÃO

Fonte: BRASIL (2013)

Os livros descritos acima fazem parte do Programa Nacional Biblioteca da Escola (PNBE) que tem como objetivo prover as escolas de ensino público das redes federal, estadual, municipal e do Distrito Federal, no âmbito da educação infantil 
(creches e pré-escolas), do ensino fundamental, do ensino médio e educação de jovens e adultos (EJA), com o fornecimento de obras e demais materiais de apoio à prática da educação básica. Todas as escolas públicas cadastradas no censo escolar são atendidas pelo programa sem necessidade de adesão.

Para conduzir este estudo, os livros dos acervos recebidos no ano de 2013 foram separados por acervos, tabulados e analisados. Foram considerados para a classificação dos livros as informações das fichas catalográficas, e os três elementos que caracterizam os gêneros discursivos como: o estilo, conteúdo temático e construção composicional, de acordo com Bakthin (2011):

\begin{abstract}
A relação orgânica e indissociável do estilo com o gênero se revela nitidamente também na questão dos estilos de linguagem ou funcionais. No fundo, os estilos de linguagem ou funcionais não são outra coisa senão estilos de gênero de determinadas esferas de atividade humana e da comunicação. Em cada campo existem e são empregados gêneros que correspondam às condições específicas de cada campo; é a esses gêneros que correspondem determinados estilos. Uma determinada função (científica, técnica, ideológica, oficial, cotidiana) e determinadas condições de comunicação discursiva, específicas de cada campo, geram determinados gêneros, isto é, determinados tipos de enunciados estilísticos, temáticos e composicionais relativamente estáveis. O estilo é indissociável de determinadas unidades temáticas e - o que é de especial importância- de determinadas unidades composicionais: de determinados tipos de construção do conjunto, de tipos do seu acabamento, de tipos da relação do falante com outros participantes da comunicação discursiva- com os ouvintes, os leitores, os parceiros, o discurso do outro, etc. $\mathrm{O}$ estilo integra a unidade do gênero do enunciado como seu elemento. (BAKTHIN, 2011, p. 266)
\end{abstract}

Após esses procedimentos, os livros foram agrupados por gêneros, quantificados e tabulados conforme foram encontrados por caixas, para nortearem as sugestões de atividades de leitura.

\title{
RESULTADOS
}

Para a classificação dos livros que compõem os acervos I, II e III do ano de 2013, recebidos pelo Ministério da Educação (MEC) do Programa Nacional Biblioteca na Escola (PNBE), foi realizada a análise utilizando as fichas catalográficas presentes em cada unidade e também os critérios de classificação dos gêneros discursivos. O quadro 1, a seguir, apresenta essa classificação e divisão por caixas: 
Quadro 1- Classificação dos livros por gêneros

\begin{tabular}{|c|c|c|}
\hline Título do livro & & Gênero \\
\hline A Filha das Sombras & \multirow[t]{17}{*}{$\mathrm{C} 1$} & \multirow{47}{*}{ Conto } \\
\hline A mocinha do Mercado Central & & \\
\hline Antologia de Contos Folclóricos & & \\
\hline Aqualtune e as Histórias da África & & \\
\hline As Aventuras de Tom Sawyer & & \\
\hline As Melhores Histórias das Mil e Uma Noites & & \\
\hline Duelo & & \\
\hline Era uma vez à Meia Noite & & \\
\hline Histórias Arrepiantes de Crianças- Prodígio & & \\
\hline O Chamado do Mostro & & \\
\hline O enigma de Iracema & & \\
\hline O Homão e o Menininho & & \\
\hline O Leão da Noite Estrelada & & \\
\hline O Livro Negro de Tomas Kyd & & \\
\hline Os Pequenos Verdes e Outras Histórias & & \\
\hline Robin Hood & & \\
\hline Sortes de Villamor & & \\
\hline Tem Um Morcego no Meu Pombal & \multirow[t]{13}{*}{$\mathrm{C} 2$} & \\
\hline As Mil e Uma Noites & & \\
\hline A Reforma da Natureza & & \\
\hline A Roda do Vento & & \\
\hline A Tatuagem-Reconto do Povo Luo & & \\
\hline Com Certeza Tenho Amor & & \\
\hline É Fogo! & & \\
\hline Mary Shelley: O Mistério da Imortalidade & & \\
\hline O Chute que que Bola Levou & & \\
\hline O Flautista de Hamelin & & \\
\hline O Gato do Xeique e outras Lendas & & \\
\hline O que a Terra está falando? & & \\
\hline O Outro Passo da Dança & & \\
\hline A Jornada & \multirow[t]{17}{*}{$\mathrm{C} 3$} & \\
\hline A Vaca na Selva & & \\
\hline A Volta às Aulas do Pequeno Nicolau? & & \\
\hline As Memórias de Eugênia & & \\
\hline Era uma vez Esopo & & \\
\hline Fantástica Fábrica de Chocolate & & \\
\hline Histórias de Bichos & & \\
\hline Histórias de Mistério & & \\
\hline Justino, o Retirante & & \\
\hline Moby Dick & & \\
\hline O Livro dos Dragões & & \\
\hline O Livro Selvagem & & \\
\hline O Mistério do Cinco Estrelas & & \\
\hline O Senhor dos Ladrões & & \\
\hline Pão Feio em Casa- Três Jovens. Uma Receita. Alguns Segredos & & \\
\hline Se a Memória não me falha & & \\
\hline Você é Livre! & & \\
\hline Anita Garibaldi- A Estrela da Tempestade & \multirow[t]{2}{*}{$\mathrm{C} 1$} & \multirow{4}{*}{ Biografia } \\
\hline Charles Darwin: O Segredo da Evolução & & \\
\hline Fotografando Verger & \multirow[t]{2}{*}{$\mathrm{C} 2$} & \\
\hline Três Anjos Mulatos do Brasil & & \\
\hline As Aventuras de Max e Seu Olho Submarino & \multirow[t]{2}{*}{$\mathrm{C} 1$} & \multirow[b]{4}{*}{ Poema } \\
\hline Viagem numa Peneira & & \\
\hline Meu Coração É tua Casa & $\mathrm{C} 2$ & \\
\hline Menino do Mato & & \\
\hline
\end{tabular}




\begin{tabular}{|c|c|c|}
\hline Menino Perplexo & \multirow[t]{2}{*}{$\mathrm{C} 3$} & \\
\hline \multicolumn{2}{|l|}{$\begin{array}{l}\text { O Tempo Escapou do Relogio e Outros Poemas } \\
\text { Poetrix }\end{array}$} & \\
\hline A Criação das Criaturas & C3 & $\begin{array}{c}\text { Verbete ficcional de } \\
\text { enciclopédia }\end{array}$ \\
\hline Diário do Outro & \multirow{3}{*}{$\mathrm{C} 1$} & \multirow{3}{*}{ Diário } \\
\hline O Cara & & \\
\hline O Diário de Dan & & \\
\hline O Desaparecimento de KatharinaLinden & $\mathrm{C} 1$ & \multirow{5}{*}{ Romance } \\
\hline 1001 Fantasmas & \multirow[t]{2}{*}{$\mathrm{C} 2$} & \\
\hline Os Noivos & & \\
\hline Atrás do Paraíso & \multirow[t]{2}{*}{$\mathrm{C} 3$} & \\
\hline Isso ninguém me tira & & \\
\hline O Livreiro do Alemão & $\mathrm{C} 1$ & Memórias \\
\hline O Mundo de Camila & $\mathrm{C} 1$ & \multirow{4}{*}{ Novela } \\
\hline A Primeira Vez que Vi Meu Pai & \multirow[t]{2}{*}{$\mathrm{C} 2$} & \\
\hline O Burrinho Pedrês & & \\
\hline Desculpe a nossa falha & C3 & \\
\hline Os Passarinhos e Outros Bichos & $\mathrm{C} 1$ & \multirow{5}{*}{ História em Quadrinhos } \\
\hline A Escrava Isaura & \multirow[t]{2}{*}{$\mathrm{C} 2$} & \\
\hline Pescador de Ilusões & & \\
\hline O Fantasma de Canterville & \multirow[t]{2}{*}{$\mathrm{C} 3$} & \\
\hline Orixás: Do Orum ao Ayê & & \\
\hline Dom Quixote em Cordel & \multirow[t]{2}{*}{$\mathrm{C} 2$} & \multirow[t]{2}{*}{ Cordel } \\
\hline Sete Histórias de Pescaria do Seu Vivinho & & \\
\hline Livro de Recados & $\mathrm{C} 2$ & Recados \\
\hline Moça Lua e Outras Lendas & $\mathrm{C} 2$ & Lendas \\
\hline O Doente Imaginário & \multirow[t]{2}{*}{$\mathrm{C} 2$} & \multirow{3}{*}{ Teatro } \\
\hline Sangue de Dragão- Palco de Paixões & & \\
\hline A Fábrica de Robôs & $\mathrm{C} 3$ & \\
\hline Ninguém me entende nessa casa! & $\mathrm{C} 3$ & Crônica \\
\hline Raul Taburin & $\mathrm{C} 3$ & Fábula \\
\hline
\end{tabular}

Fonte: Corpus da pesquisa

\section{PROPOSTAS DE ATIVIDADES}

Após a organização por títulos conforme os gêneros, a pesquisadora propôs sugestões de atividades diversificadas:

\section{Organização da sala em estações de acordo com os gêneros encontrados}

Como nem todas as escolas possuem bibliotecas ou espaços adequados para a leitura, a sala de aula poderá ser organizada para esse fim. A sugestão é que os livros dos acervos sejam organizados por gêneros em estações. 
A divisão por estações foi inspirada e adaptada no ensino híbrido, também chamado de blended learning, em que o método alterna momentos em que o aluno estuda sozinho - em geral em ambiente virtual - e em grupo, quando interage com seus colegas e o professor. A intenção é que o aluno seja protagonista e busque o conhecimento segundo seus próprios interesses, nesse caso, em que a leitura é o foco, o aluno selecionará o gênero que mais lhe agrade e lhe de prazer, deixando de ser uma leitura imposta e sem sentido.

Por essa organização, cada sala de aula terá 10 estações. Alguns gêneros foram agrupados, utilizando os critérios de proximidade das características composicionais e estilo. A seguir seguem as sugestões de estações para a organização dos livros em sala de aula:

1- Estação Biografia

2- Estação Recados

3- Estação Contos/Lendas/Novelas/Romance

4- Estação Poemas e Cordel

5- Estação Memórias e Diário

6- Estação História em Quadrinhos

7- Estação Teatro

8- Estação Verbete ficcional de enciclopédia

9- Estação Crônica

10- Estação Fábula

Em cada estação o professor poderá realizar atividades de leitura sobre os diferentes gêneros. E para esse trabalho com a leitura dos gêneros o professor poderá utilizar procedimentos que envolvam atividades antes, durante e depois da leitura. Essas propostas podem ser incorporadas à prática de leitura em sala de aula visando a formação de um cidadão mais proficiente e crítico. Cada estação deverá considerar, nos procedimentos de leitura, as especificidades de cada gênero a ser lido.

\section{Sugestões de atividades para a leitura na estação}

- Levantamento dos conhecimentos prévios sobre o (s) gênero (s) da estação e dos alunos que vão escolher os livros. 
- Leitura global do livro escolhido e estabelecimento de objetivos de leitura de acordo com o gênero e o tema do livro.

- Apreciação crítica do livro escolhido com sugestões de produção de gráficos, produção em grupo de "Nuvem de Palavra" e exposição oral sobre os livros lidos por estação.

\section{Detalhamento das atividades por estação}

Os quadros a seguir apresentam sugestões de perguntas para cada etapa de leitura, de acordo com o (s) gênero (s) de cada estação.

\section{Estação Biografia}

\begin{tabular}{|c|c|}
\hline \multicolumn{2}{|c|}{ Ficha de Leitura- Estação Biografia } \\
\hline $\begin{array}{l}\text { 1. Levantamento dos conhecimentos prévios } \\
\text { do gênero }\end{array}$ & $\begin{array}{l}\text { - O que é uma biografia? } \\
\text { - Qual é o propósito/a finalidade desse } \\
\text { gênero? } \\
\text { - Por que as pessoas gostam de ler } \\
\text { biografias? }\end{array}$ \\
\hline $\begin{array}{l}\text { 2. Leitura global da capa e outros elementos } \\
\text { destacados do livro e estabelecimento de } \\
\text { objetivos de Leitura }\end{array}$ & $\begin{array}{l}\text { - Quem será a pessoa sobre a qual foi } \\
\text { escrita a biografia } \\
\text { - Você sabe alguma informação sobre essa } \\
\text { - } \quad \text { O que você quer saber sobre essa pessoa? } \\
\text { - O que essa pessoa fez de interessante para } \\
\quad \text { ter uma biografia? }\end{array}$ \\
\hline 3. Apreciação crítica & $\begin{array}{ll}\text { - } & \text { Produção de gráficos } \\
\text { - } & \text { Produção de nuvem de palavras } \\
\text { - } & \text { Exposição oral sobre os livros lidos }\end{array}$ \\
\hline
\end{tabular}

\section{Estação Recados}

\begin{tabular}{|c|c|}
\hline \multicolumn{2}{|c|}{ Ficha de Leitura- Estação Recados } \\
\hline $\begin{array}{l}\text { 1. Levantamento dos conhecimentos prévios } \\
\text { do Gênero }\end{array}$ & $\begin{array}{l}\text { - Que texto é esse? } \\
\text { - Para que serve? }\end{array}$ \\
\hline $\begin{array}{l}\text { 2. Leitura global da capa e outros elementos } \\
\text { destacados do livro e estabelecimento de } \\
\text { objetivos de Leitura }\end{array}$ & $\begin{array}{l}\text { - Pelo título: Qual será o assunto desse livro? } \\
\text { - Quem é o autor? Você já o conhece? } \\
\text { - Para quem e por que a personagem escreve os } \\
\text { recados? }\end{array}$ \\
\hline 3. Apreciação crítica & $\begin{array}{l}\text { - } \quad \text { Produção de gráficos } \\
\text { - } \quad \text { Produção de nuvem de palavras } \\
\text { - } \quad \text { Exposição oral sobre os livros lidos }\end{array}$ \\
\hline
\end{tabular}




\section{Estação Contos/Lendas/Novelas/Romance}

\begin{tabular}{|c|c|}
\hline \multicolumn{2}{|c|}{ Ficha de Leitura- Estação Contos/Lendas/Novelas/Romance } \\
\hline $\begin{array}{l}\text { 1. Levantamento dos conhecimentos prévios } \\
\text { do Gênero }\end{array}$ & $\begin{array}{l}\text { - O que é um conto/ lenda/ novela/ romance? } \\
\text { Com que propósito comunicativo/objetivo um } \\
\text { autor escreve um conto/ lenda/ novela/ } \\
\text { romance? } \\
\text { - Quais os temas possíveis abordados pelo conto/ } \\
\text { lenda/ novela/ romance? }\end{array}$ \\
\hline $\begin{array}{l}\text { 2. Leitura global da capa e outros elementos } \\
\text { destacados do livro e estabelecimento de } \\
\text { objetivos de Leitura }\end{array}$ & $\begin{array}{l}\text { - Quem é o autor? Você já o conhece? } \\
\text { - Pelo título: Qual será o assunto desse conto/ } \\
\text { lenda/ novela/ romance? } \\
\text { - Pela capa e ilustrações: O que pode ter } \\
\text { acontecido? }\end{array}$ \\
\hline 3. Apreciação crítica & $\begin{array}{l}\text { - } \text { Produção de gráficos } \\
\text { - Produção de nuvem de palavras } \\
\text { - Exposição oral sobre os livros lidos }\end{array}$ \\
\hline
\end{tabular}

\section{Estação Poemas e Cordel}

\begin{tabular}{|c|c|}
\hline \multicolumn{2}{|c|}{ Ficha de Leitura- Estação Poemas e Cordel } \\
\hline $\begin{array}{l}\text { 1. Levantamento dos conhecimentos prévios } \\
\text { do Gênero }\end{array}$ & $\begin{array}{l}\text { - O que é poema/cordel? } \\
\text { - Quem escreve poema/ cordel? } \\
\text { - Que temas podem ser abordados nesses } \\
\text { gêneros? } \\
\text { - Qual é o propósito/ a finalidade do } \\
\text { poema/cordel } \\
\text { - Esses gêneros têm alguma característica típica } \\
\text { na linguagem e na estrutura? } \\
\text { - Quem gosta de ler poemas? Por quê? }\end{array}$ \\
\hline $\begin{array}{l}\text { 2. Leitura global da capa e outros elementos } \\
\text { destacados do livro e estabelecimento de } \\
\text { objetivos de Leitura }\end{array}$ & $\begin{array}{l}\text { - Leia o poema/cordel } \\
\text { Depois } \\
\text { - Leia voz alta um dos poemas do livro } \\
\text { explorando a expressividade do ritmo, da } \\
\text { sonoridade, do andamento do poema, } \\
\text { especialmente quando esses elementos forem } \\
\text { marcantes no poema. } \\
\text { Quais suas impressões a respeito do poema/ } \\
\text { cordel. }\end{array}$ \\
\hline 3. Apreciação crítica & $\begin{array}{l}\text { - } \quad \text { Produção de gráficos } \\
\text { - } \quad \text { Produção de nuvem de palavras } \\
\text { - } \quad \text { Exposição oral sobre os livros lidos }\end{array}$ \\
\hline
\end{tabular}

\section{Estação Memórias e Diário}

\begin{tabular}{|l|l|}
\hline \multicolumn{2}{|c|}{ Ficha de Leitura- Estação Memória e Diário } \\
\hline $\begin{array}{l}\text { 1. Levantamento dos conhecimentos prévios } \\
\text { do Gênero }\end{array}$ & $\begin{array}{l}\text { O que é memória/diário? } \\
\text { - Qual é o propósito/a finalidade desse gênero? } \\
\text { - Por que as escrevem memória/diário? }\end{array}$ \\
\hline $\begin{array}{l}\text { 2. Leitura global da capa e outros elementos qu as pessoas gostam de ler } \\
\text { destacados do livro e estabelecimento de de } \\
\text { objetivos de Leitura }\end{array}$ & $\begin{array}{l}\text { Leitura global (título, imagens, autor, local e ano } \\
\text { de publicação); reconhecimento do gênero; } \\
\text { estabelecimento de objetivos de leitura a partir da } \\
\text { curiosidade pela história. } \\
\text { - Quem é esse autor? }\end{array}$ \\
\hline
\end{tabular}




\begin{tabular}{|c|c|}
\hline & $\begin{array}{l}\text { - O que o título sugere? } \\
\text { - O que ele vai contar da vida dele? }\end{array}$ \\
\hline 3. Apreciação crítica & $\begin{array}{l}\text { - } \quad \text { Produção de gráficos } \\
\text { - } \quad \text { Produção de nuvem de palavras } \\
\text { - }\end{array}$ \\
\hline
\end{tabular}

\section{Estação História em Quadrinhos}

\begin{tabular}{|l|l|}
\hline \multicolumn{3}{|c|}{ Ficha de Leitura- Estação História em Quadrinhos } \\
\hline $\begin{array}{l}\text { 1. Levantamento dos conhecimentos prévios } \\
\text { do Gênero }\end{array}$ & $\begin{array}{l}\text { O que são histórias em quadrinhos? } \\
\text { Para que servem? }\end{array}$ \\
\hline $\begin{array}{l}\text { 2. Leitura global da capa e outros das palavras, há outros elementos que } \\
\text { devem ser lidos numa HQ? }\end{array}$ \\
$\begin{array}{l}\text { elementos destacados do livro e estabelecimento de } \\
\text { objetivos de Leitura }\end{array}$ & $\begin{array}{l}\text { Pelo título: Qual será o assunto desse livro? } \\
\text { Pela capa e ilustrações: O que você acha que } \\
\text { pode ter acontecido? } \\
\text { - Algumas dessas histórias foram originalmente } \\
\text { escritas em livros e agora e estão apresentadas } \\
\text { em forma de HQ. Você conhece essas histórias? }\end{array}$ \\
\hline Apreciação crítica & $\begin{array}{l}\text { - Produção de gráficos } \\
\text { - Produção de nuvem de palavras } \\
\end{array}$ \\
\hline
\end{tabular}

\section{Estação Teatro}

\begin{tabular}{|c|c|}
\hline \multicolumn{2}{|c|}{ Ficha de Leitura- Estação Teatro } \\
\hline $\begin{array}{l}\text { 1. Levantamento dos conhecimentos prévios } \\
\text { do Gênero }\end{array}$ & $\begin{array}{l}\text { - O que é teatro? } \\
\text { - Qual é o propósito/a finalidade desse gênero? } \\
\text { - O que é necessário para uma peça de teatro } \\
\text { acontecer? } \\
\text { - Como uma peça de teatro é montada? } \\
\text { - Como os atores sabem o que têm que dizer e a } \\
\text { hora certa de fazê-lo? }\end{array}$ \\
\hline $\begin{array}{l}\text { 2. Leitura global e estabelecimento de } \\
\text { objetivos de Leitura }\end{array}$ & $\begin{array}{l}\text { - Quem é o autor? Você já o conhece? } \\
\text { - Pelo título: Qual será o assunto desse teatro? } \\
\text { - Pela capa e ilustrações: O que pode ter } \\
\text { acontecido? }\end{array}$ \\
\hline 3. Apreciação crítica & $\begin{array}{ll}\text { - } & \text { Produção de gráficos } \\
\text { - } & \text { Produção de nuvem de palavras } \\
\text { - } & \text { Exposição oral sobre os livros lidos }\end{array}$ \\
\hline
\end{tabular}

\section{Estação Verbete ficcional de enciclopédia}

\begin{tabular}{|l|l|}
\hline \multicolumn{2}{|c|}{ Ficha de Leitura- Estação Verbete de enciclopédia } \\
\hline $\begin{array}{l}\text { 1. Levantamento dos conhecimentos prévios } \\
\text { do Gênero }\end{array}$ & $\begin{array}{l}\text { O que é um verbete de enciclopédia? } \\
\text { Qual é o propósito/a finalidade desse gênero? } \\
\text { Quem conhece uma enciclopédia? } \\
\text { Você já viu ou consultou um verbete? }\end{array}$ \\
\hline $\begin{array}{l}\text { 2. Leitura global e estabelecimento de } \\
\text { objetivos de Leitura }\end{array}$ & $\begin{array}{l}\text { Esses verbetes são ficcionais. Por quê alguém } \\
\text { inventaria verbetes? } \\
\text { Que verbetes foram inventados? }\end{array}$ \\
\hline Apreciação crítica & $\begin{array}{l}\text { Produção de gráficos } \\
\text { - Produção de nuvem de palavras } \\
\end{array}$ \\
\end{tabular}


Estação Crônica

\begin{tabular}{|c|c|}
\hline \multicolumn{2}{|c|}{ Ficha de Leitura- Estação Crônica } \\
\hline $\begin{array}{l}\text { 1. Levantamento dos conhecimentos prévios do } \\
\text { Gênero }\end{array}$ & $\begin{array}{l}\text { - O que é crônica? } \\
\text { - Qual é o propósito do autor da crônica? } \\
\text { - Qual é o estilo do texto da crônica? } \\
\text { - Quem escreve crônica? } \\
\text { - Geralmente onde ela é publicada? } \\
\text { - Que temas podem ser abordados numa } \\
\text { crônica? } \\
\text { - Por que as pessoas gostam de ler } \\
\text { crônicas? }\end{array}$ \\
\hline $\begin{array}{l}\text { 2. Leitura global e estabelecimento de objetivos } \\
\text { de Leitura }\end{array}$ & $\begin{array}{l}\text { - Qual é o fato/tema que despertou a } \\
\text { atenção do cronista? } \\
\text { - Que sentimentos o autor prescreve na } \\
\text { crônica lida? }\end{array}$ \\
\hline 3. Apreciação crítica & $\begin{array}{l}\text { - } \quad \text { Produção de gráficos } \\
\text { - } \quad \text { Produção de nuvem de palavras } \\
\text { - } \quad \text { Exposição oral sobre os livros lidos }\end{array}$ \\
\hline
\end{tabular}

\section{Estação Fábula}

\begin{tabular}{|l|l|l|}
\hline \multicolumn{3}{|c|}{ Ficha de Leitura- Estação Fábula } \\
\hline $\begin{array}{l}\text { 1. Levantamento dos conhecimentos prévios } \\
\text { do Gênero }\end{array}$ & $\begin{array}{l}\text { - O que é fábula? Para que serve a fábula? } \\
\text { Que assuntos podem ser abordados numa } \\
\text { fábula? } \\
\text { - Você conhece a origem das fábulas? }\end{array}$ \\
\hline $\begin{array}{l}\text { 2. Leitura global e estabelecimento de } \\
\text { objetivos de Leitura }\end{array}$ & $\begin{array}{l}\text { Quem são as personagens da fábula? } \\
\text { - O que aconteceu com eles? }\end{array}$ \\
\hline Apreciação crítica & $\begin{array}{l}\text { Que comportamentos das pessoas essa fábula } \\
\text { aborda? }\end{array}$ \\
\hline & $\begin{array}{l}\text { - Produção de gráficos } \\
\text { - Produção de nuvem de palavras }\end{array}$ \\
& \begin{tabular}{l} 
- Exposição oral sobre os livros lidos \\
\hline
\end{tabular}
\end{tabular}

\section{Apreciação crítica do livro escolhido}

A partir dos procedimentos de leitura apresentados anteriormente, a pesquisadora sugere ao professor algumas atividades após a leitura para uma reflexão crítica sobre o livro lido. Como sugestões de atividades, podem ser citadas a exposição da opinião pessoal da leitura realizada e até mesmo uma troca de ideias sobre o livro escolhido. Cada aluno avaliará os livros lidos, emitindo a sua opinião, sugerindo ao colega a leitura e registrando suas impressões. Para isso sugere-se que em cada estação os alunos utilizem-se da produção de gráficos com emoticons, pesquisa interativa com produção de nuvem de palavras e ou exposição oral na roda de conversa para enunciar suas opiniões. 


\section{Produção de gráfico com emoticons:}

Para a realização dessa atividade o professor disponibilizará uma tabela como a do exemplo a seguir, juntamente com a cartela auto adesiva de emoticons. Cada aluno escolherá o emoticon que mais representa a opinião sobre o livro lido, colará na estação correspondente e registrará o nome do livro lido na tabela. Assim comporá o gráfico: "O que achamos dos livros lidos". Ao final o professor poderá explorar o gráfico oralmente sobre o gênero preferido da turma, qual o mais lido e se a turma apresentou satisfação com a atividade proposta. O gráfico poderá ser exposto na sala de aula e ou na biblioteca da escola.

O gráfico abaixo é um exemplo de uma estação. Para cada estação haverá um gráfico com os livros correspondentes àquela estação.

\begin{tabular}{|l|l|l|l|}
\hline \multicolumn{3}{|c|}{ Estação Biografia } \\
Gráfico dos Livros Lidos \\
\hline \multicolumn{2}{|c|}{ Livros $\quad$ Estrela da } & & \\
\hline $\begin{array}{l}\text { Anita Garibaldi- } \\
\text { Tempestade }\end{array}$ & & \\
\hline Charles Darwin: O Segredo da Evolução & & \\
\hline Fotografando Verger & & \\
\hline Três Anjos Mulatos do Brasil & & & \\
& & & \\
\hline
\end{tabular}

\section{Pesquisa interativa com produção de nuvem de palavras.}

Nesta atividade, a pesquisadora sugere que o professor realize a pesquisa interativa sobre a apreciação crítica dos alunos em relação aos livros lidos e após a pesquisa os alunos acessarão um link para a produção de nuvens de palavras. 
As nuvens de palavras são imagens formadas com palavras de várias fontes. Estas palavras podem ser extraídas de uma aula, de um site, poema, história ou mesmo palavras aleatórias de qualquer escolha. A quantidade de vezes que uma única palavra é colocada em uma nuvem determinará o tamanho daquela palavra dentro do objeto de escolha. É uma ferramenta da internet, bastante criativa e que não requer o domínio de qualquer habilidade em especial para uitlizá-la.

A nuvem de palavras produzidas em sala conterá todas as palavras que os alunos utilizaram para expressar suas opiniões e propiciará ao professor explorar de diversas maneiras as produções dos alunos. Ao final, as nuvens de palavras poderão ser expostas na sala de aula e ou na biblioteca, como se sugeriu na atividade anterior.

\begin{tabular}{|l|l|}
\hline 1 & Você gostou do livro escolhido? Por quê? \\
\hline 2 & Você gostou da maneira como o autor (a) escreveu? \\
\hline 3 & Você recomendaria essa leitura para um colega? \\
\hline 4 & Escolha 10 palavras para definir a sua opinião sobre o livro. \\
\hline
\end{tabular}

Após as respostas, os alunos escolherão e acessarão um dos links abaixo para produzir a nuvem de palavras referente a questão 4 .

$\underline{\text { www.tagxedo.com }}$

www.tagul.com

www.tagcrowd.com

\section{http://www.wordle.net/}

Caso, os professores e alunos encontrem dificuldades poderão acessar o endereço abaixo para assisitir ao tutorial para a produção de nuvem de palavras. 
O exemplo a seguir de nuvem de palavras foi produzido a partir do resumo do presente artigo.

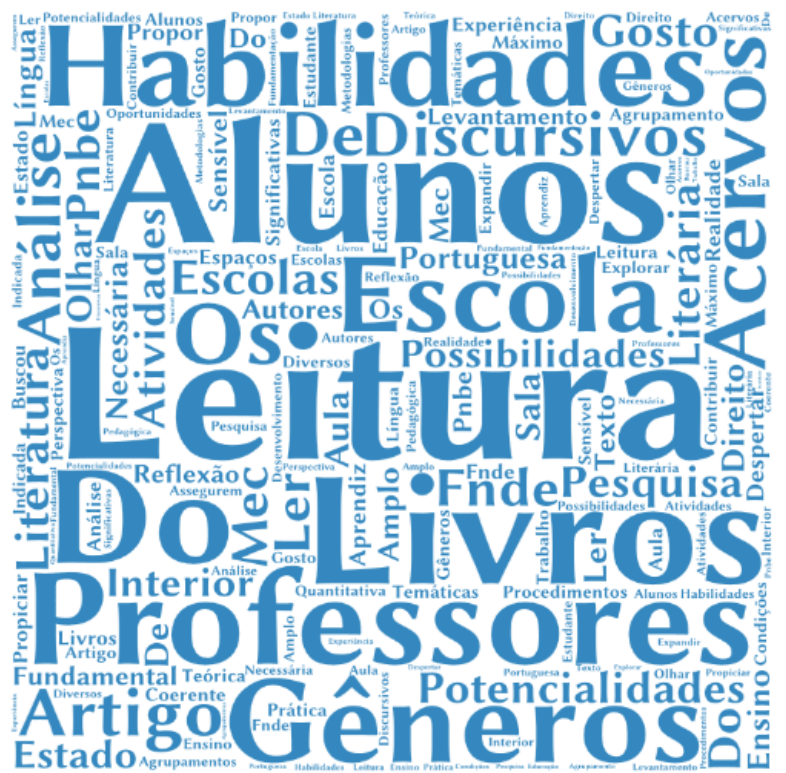

\section{Exposição oral na roda de conversa}

A roda de conversa tem como objetivo incentivar os participantes a comentarem a opinião pessoal sobre a obra lida. Espera-se que essa atividade, em que alunos e professores em roda conversam sobre os livros, seja um momento propício para todos os envolvidos manifestarem seus sentimentos e opiniões sobre os livros trabalhados, assim como também, um espaço que estimule comentários e discussões sobre peculiaridades das obras.

\section{CONCLUSÃO}

Esta pesquisa teve por objetivo geral contribuir para o trabalho didático com a leitura no Ensino Fundamental II. Especificamente objetivou em fazer um levantamento e uma análise dos acervos de livros oferecidos pelo FNDE/PNBE (MEC) a fim de agrupá-los por gêneros discursivos e propor atividades de leitura significativas para que os professores os usem com mais frequência, explorando melhor suas potencialidades e fomentado a leitura na escola, de acordo com os pressupostos teóricos desta pesquisa.

Para cada um dos agrupamentos apresentou a sequência didática de leitura enfocando estratégias antes, durante e depois como possibilidades facilitadoras para um trabalho mediado pelo professor, despertando o gosto pela leitura e o interesse dos alunos por livros para que adquira o domínio desta habilidade. Por fim, espera-se que as 
atividades de leitura propostas neste estudo, sejam bem-sucedidas, de modo aguçar a vontade de ler propiciando uma relação aproximada e significativa dos livros.

\section{REFERÊNCIAS}

BAKHTIN, M. Estética da criação verbal. 6 ed. São Paulo: Martins Fontes, 2011.

CANDIDO, Antonio. Vários Escritos. Editora Duas Cidades, 1995.

CEREJA, W. R. Ensino da literatura: uma proposta dialógica para o trabalho com literatura. São Paulo: Ática, 2005.

COELHO, Nelly Novaes. Literatura: arte, conhecimento e vida. São Paulo: Peirólopis, 2000 .

COELHO, Nelly Novaes. Literatura Infantil: teoria, análise e didática. São Paulo: Moderna, 2000.

DALVI, Maria A. Literatura na escola: propostas didático-metodológicas. In: DALVI, Maria A.; REZENDE, Neide L. de; JOVER-FALEIROS, Rita. (Org.). Leitura de literatura na escola. São Paulo: Parábola, 2013. p. 67-96.

DALVI, Maria A.; REZENDE, Neide L. de; JOVER-FALEIROS, Rita. (Org.). Leitura de literatura na escola. São Paulo: Parábola, 2013.

LOPES-ROSSI, M.A. G. A formação do leitor proficiente e crítico a partir das características específicas dos gêneros discursivos. Intercâmbio, 2005. P. 1-10.

MARIA, de Luiza. Leitura \& colheita. Livros, leitura e formação de leitores. Editora Vozes, Petrópolis, 2008.

PINTO, Francisco Neto Pereira. Por um ensino literário complexo. Leitura: Teoria \& Prática, Campinas, v.32, 2014, p. 115-127.

\section{A AUTORA}

Juliana Aparecida Melo Almeida da Silva é mestre em Linguística Aplicada pela Universidade de Taubaté, pós graduada em Gestão Escolar pela FINOM, pós graduada em Leitura e Produção de Textos e graduada em Letras pela Universidade de Taubaté. Cursou Aperfeiçoamento em Gestão da Educação Básica pela Universidade Federal de Juiz de Fora. Desde1999 tem experiência em Educação, atua como professora de Língua Portuguesa, Literatura e Redação no Ensino Médio em escolas particulares e como professor coordenador formador na Secretaria Municipal de Campos do Jordão. 